\title{
Emergência de intraverbais a partir do treino de tatos com Precision Teaching
}

\section{Emergency of intraverbais from tact training with Precision Teaching \\ Emergencia de intraverbales a partir del entrenamiento de tatos con Precision Teaching}

\author{
Priscilla Terumi Moraes ${ }^{1}$, Cláudia Stefânia Figueiredo Neves Coimbra²
}

\footnotetext{
[1] \{2] Paradigma - Centro de Ciências do Comportamento - Paranaíba, Pontifícia Universidade Católica de São Paulo (PUC-SP) I Título abreviado: Emergência de intraverbais via tatos e Precision Teaching I Endereço para correspondência: Priscilla Terumi Moraes Av. Ibirapuera, 2120 - Conjunto 151 Moema - SP I Email: priscilla.terumi1@gmail.com I doi: 10.18761/PAC.2020.v11.n2.10
}

Resumo: Indivíduos com TEA (Transtorno do Espectro do Autismo) podem apresentar dificuldades de comunicação, tais como déficits na emissão de intraverbais durante interação social. Ao longo dos anos, pesquisadores vêm testando diversos procedimentos para o ensino desta habilidade (Kodak, Fuchtman e Paden (2012); McMorrow, Foxx, Faw, e Bittle (1987); Cihon, White, Zimmerman, Gesick, Stordahl \& Eshleman (2017)). Este trabalho objetivou avaliar se o ensino de tatos tematicamente relacionados a níveis fluentes poderia resultar na emergência de intraverbais. Utilizou-se delineamento de linha de base múltipla entre categorias, de sujeito único, e foram realizadas cinco etapas de ensino: (1) treino de tato, (2) treino de fluência de tato, (3) sonda de persistência (endurance), (4) sonda de estabilidade (stability) e (5) sonda de retenção (retention). Os resultados indicaram que a habilidade intraverbal emergiu a partir do treino fluente de tatos tematicamente relacionados com uso de Ensino Preciso (Precision Teaching), sem necessidade de treino direto. Estudos futuros podem investigar a emergência com indivíduos que não emitem intraverbais para nenhuma categoria, $\mathrm{e}$ também comparar o tempo de aquisição entre o treino direto e o treino de fluência de tato com um mesmo sujeito. O presente estudo apresenta limitações quanto ao contexto no qual foi realizado e participante (setting terapêutico e história de reforçamento de seguir instruções), e quanto à forma de apresentação dos estímulos (sinalização das categorias temporal e visualmente).

Palavras-chave: intraverbal; precision teaching; tato; autismo. 


\begin{abstract}
Individuals with ASD (Autism Spectrum Disorder) may experience communication difficulties, such as deficits in the emission of intraverbal during social interaction. Over the years, researchers have been testing various procedures for teaching this skill (Kodak, Fuchtman and Paden (2012); McMorrow, Foxx, Faw, and Bittle (1987); Cihon, White, Zimmerman, Gesick, Stordahl \& Eshleman (2017)). This work aimed to evaluate whether the teaching of tacts thematically related to fluent levels could result in the emergence of intraverbals. A multiple baseline design was used between categories, of a single subject, and five teaching stages were performed: (1) tact training, (2) tact fluency training, (3) persistence probe (endurance), (4) stability probe and (5) retention probe. The results indicated that the intraverbal skill emerged from the fluent training of tacts thematically related to the use of Precision Teaching, without the need for direct training. Future studies can investigate the emergency with individuals who do not emit intraverbal for any category, and also compare the acquisition time between direct training and tact fluency training with the same subject. The present study has limitations regarding the context in which it was performed and participant (therapeutic setting and reinforcement history of following instructions), as well as the form of presentation of the stimuli (signaling of the temporal and visual categories).
\end{abstract}

Keywords: intraverbal; precision teaching; tact; autism.

Resumen: Las personas con TEA (trastorno del espectro autista) pueden experimentar dificultades de comunicación, como déficits en la emisión de intraverbales durante la interacción social. A lo largo de los años, los investigadores han estado probando varios procedimientos para enseñar esta habilidad (Kodak, Fuchtman y Paden (2012); McMorrow, Foxx, Faw y Bittle (1987); Cihon, White, Zimmerman, Gesick, Stordahl \& Eshleman (2017). )). Este trabajo tuvo como objetivo evaluar si la enseñanza de tactos relacionados temáticamente con niveles de fluidez podría resultar en la aparición de intraverbales. Se utilizó un diseño de línea base múltiple entre categorías, de un solo tema, y se realizaron cinco etapas de enseñanza: (1) entrenamiento de tacto, (2) entrenamiento de fluidez del tacto, (3) sonda de persistencia (resistencia), (4) sonda de estabilidad y (5) sonda de retención. Los resultados indicaron que la habilidad intraverbal surgió del entrenamiento fluido de tactos relacionados temáticamente con el uso de la Enseñanza de Precisión, sin necesidad de entrenamiento directo. Los estudios futuros pueden investigar la emergencia con individuos que no emiten intraverbales para ninguna categoría, y también comparar el tiempo de adquisición entre el entrenamiento directo y el entrenamiento de fluidez táctil con el mismo sujeto. El presente estudio tiene limitaciones en cuanto al contexto en el que se realizó y participante (escenario terapéutico e historial de reforzamiento del seguimiento de instrucciones), así como la forma de presentación de los estímulos (señalización de las categorías temporal y visual).

Palabras clave: intraverbal; precision teaching; tato; autismo. 


\section{Introdução}

O Transtorno do Espectro do Autismo (TEA) é caracterizado por déficits e excessos comportamentais, relacionados às áreas de comunicação e interação social, padrões restritos e repetitivos de comportamento, hiper ou hipo reatividade a estímulos sensoriais do ambiente, gerando prejuízos nas áreas social, ocupacional e/ou outras do funcionamento (APA, 2013). Um dos déficits na área de comunicação pode envolver a emissão de operantes verbais descritos por Skinner (1978 [1957]) como intraverbais.

De acordo com Matos, M. A. D. (1991), o operante intraverbal diz respeito a contingências envolvendo um Sd de cadeias ou conjuntos de associações verbais (visuais ou auditivos), uma resposta vocal ou motora (escrever), a consequência reforçadora é social (aprovação) e a relação entre estímulo e resposta é dada pelo controle contextual (emissão extensa). Ainda segundo a autora, eles são gerados lentamente, por reforçamento intermitente, a relação entre estímulo e resposta não tem correspondência ponto-a-ponto com o estímulo verbal de controle, e pode ocorrer como troca entre dois oradores ou como parte de uma cadeia verbal. Está presente, por exemplo, nas habilidades de completar músicas, frases e responder a perguntas. Como, por exemplo responder "Espalha a rama pelo chão" frente a "Batatinha quando nasce".
Diferentes procedimentos vêm sendo estudados para favorecer a aquisição de intraverbais com indivíduos com TEA, tais como transferência de controle de estímulos, ensino por múltiplos exemplares e equivalência [i.e. Goldsmith, Leblanc e Sautter (2007); Stauch, LaLonde, Plavnick, Bak e Gatewood (2017); Allan, Vladescu, Kisamore, Reeve e Sidener (2015)]; . Kodak, Fuchtman e Paden (2012) avaliaram três procedimentos para aquisição de intraverbal em duas crianças com TEA: (1) Dicas ecoicas com correção de erro (consistia em: (a) Terapeuta fazia uma das perguntas, (b) esperava o atraso de tempo correspondente ao critério da tentativa (hierarquia de ajuda de atraso progressivo), (c) fornecia a ajuda ecoica se a resposta correta não aparecia no atraso dado, e (d) esperava por até 5 segundos para a resposta correta com ajuda ocorrer. Se a criança não emitisse a resposta correta sem ajuda, o terapeuta corrigia repetindo a tentativa até que o participante respondesse corretamente antes da ajuda ou o terapeuta repetia a tentativa 5 vezes); (2) Dicas de tato com correção de erro (consistia em seguir os procedimentos e consequências para respostas corretas descritas do treino com dica ecoica, com uma mudança: ao invés de fornecer a ajuda ecoica o terapeuta apresentava uma ajuda de tato, segurando uma figura que correspondia a resposta correta por $5 \mathrm{~s}$. O terapeuta não dizia o nome do item em nenhum momento. O procedimento de correção era idêntico ao descrito em dica ecoica, mas

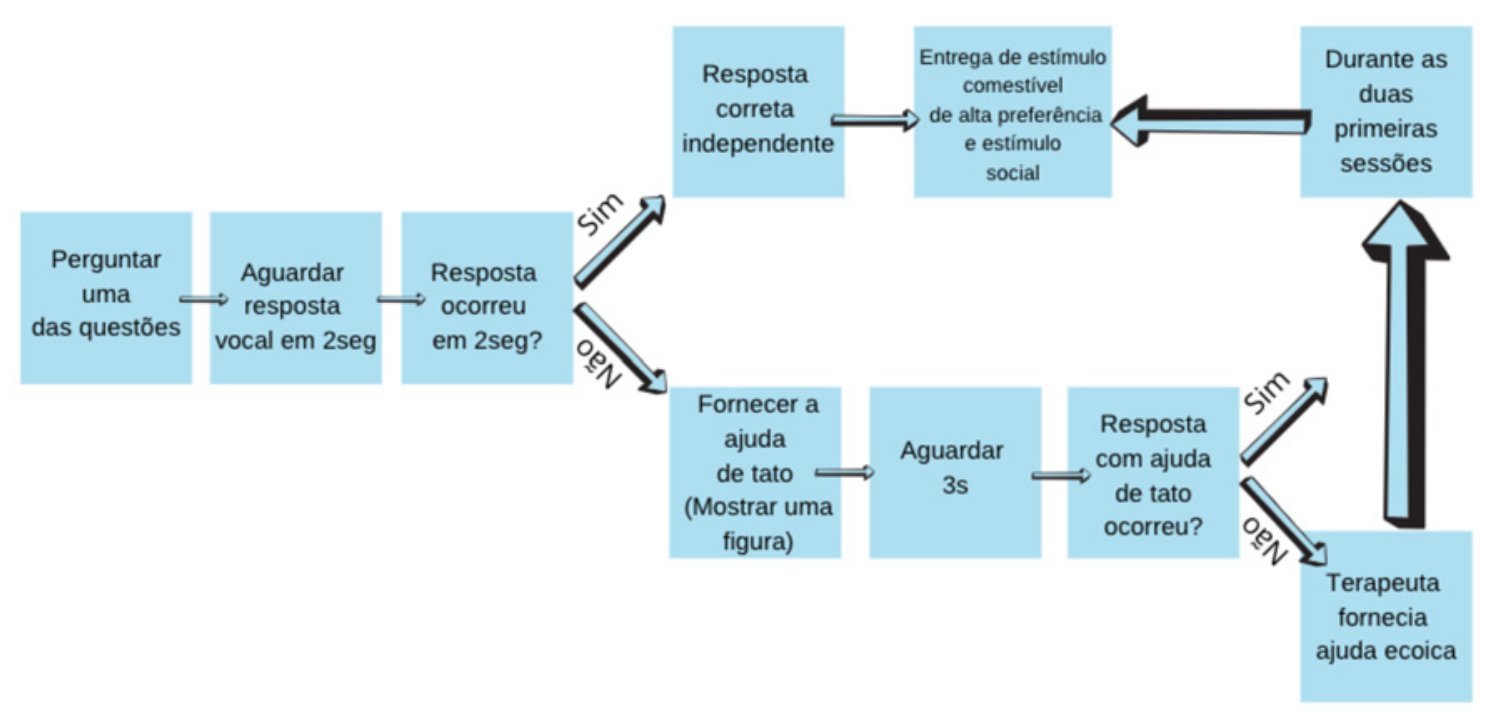

Figura 1 - Fluxograma da tentativa de ensino do Procedimento de CPP de Kodak, Fuchtman e Paden (2012) 
ao invés de fornecer dica ecoica, a dica era de tato (somente apresentação da figura, sem estímulo vocal) e (3) Procedimento cues-pause-point (CPP). O treino continha 12 tentativas (três intraverbais que eram repetidos quatro vezes). Cada tentativa incluía uma sequência de passos, como ilustrado na Figura 1.

Se a criança não emitisse uma resposta correta com dica durante a tentativa, o pesquisador fazia a correção de erro (o terapeuta repetia a pergunta e fornecia uma ajuda ecoica), repetindo a tentativa até que o participante respondesse corretamente antes da dica ou o terapeuta repetia a tentativa cinco vezes. Na primeira condição de dica, foi usado atraso de dica, iniciando com 0 s. O experimentador aumentava o atraso em $1 \mathrm{~s}$ a cada sessão (até chegar a 10 s) se em mais de $50 \%$ das tentativas tivesse ausência de resposta. Os erros também eram considerados, uma vez que se eles aparecessem em metade das tentativas, os pesquisadores não aumentavam os segundos para dica.

No procedimento de dica de tato mais correção de erro, os procedimentos e as consequências para a resposta correta eram idênticos à condição de dica ecoica mais correção de erro, com uma exceção. Ao invés de fornecer uma dica ecoica durante a tentativa de dica imediata ou quando o participante não engajava em uma resposta correta sem dica, o terapeuta apresentava uma dica de tato segurando uma figura que servia como dica visual para que o participante emitisse o tato com a resposta correta em até $5 \mathrm{~s}$. O procedimento de correção era idêntico ao da condição de dica ecoica, exceto que a dica era uma figura ao invés do estímulo vocal.

No procedimento de Cues-pause-point (CPP), Kodak, Fuchtman e Paden (2012) utilizaram o modelo de McMorrow, Foxx, Faw e Bittle (1987). Cada tentativa tinha duas partes. Na primeira parte, o terapeuta colocava a figura correspondente com a resposta correta na mesa em frente ao participante, levantava seu dedo indicador até a altura dos olhos e fazia a pergunta. Se o participante falasse antes do terapeuta mover o dedo, o terapeuta colocava o dedo na direção da boca e dizia "shhh" e colocava o dedo na altura do olho. Uma vez que a criança ficasse em silêncio por aproximadamente $2 \mathrm{~s}$, o terapeuta movia o dedo da altura do olho para apontar a carta na mesa. Se a criança não nomeasse a figura em 2 s, o terapeuta cobria a figura com os dedos por 3s. As respostas corretas eram consequenciadas com um item tangível e elogio. Se o participante não emitisse uma resposta correta de tato, o terapeuta fornecia dica ecoica e entregava um item tangível e elogio apenas para as primeiras duas sessões desta condição.

Os componentes do CPP (como o "shh") podem ter funcionado como uma punição para todo o comportamento vocal e diminuíram imediatamente todos os comportamentos vocais que se seguiram à implementação com um dos participantes. A condição de dica ecoica com correção de erro foi a mais eficaz. Este componente pode ter permitido oportunidades adicionais para o comportamento ecoico surgir sob o controle de estímulo adequado devido ao reforçamento diferencial do comportamento ecoico somente quando este era seguido de dica ecoica e não quando era seguido de perguntas. Já os procedimentos de dica de tato com correção de erro e CPP não incluíram as mesmas oportunidades porque uma resposta correta com ajuda ocorria na presença de um estímulo não verbal, ao invés de um estímulo verbal. É possível que a dica ecoica favorecia a transferência de controle de estímulos (vocal-vocal, não arbitrária), enquanto que na relação figura-vocal, do tato, a relação entre antecedente e resposta é arbitrária.

Grannan e Rehfeldt (2012) estudaram o papel da instrução de tato (esta instrução consistia em apresentar a figura com um estímulo e aguardar a criança nomear a figura, por exemplo, em uma figura com uma bola, a criança responder vocalmente «bola») em categoria para facilitar a emergência de intraverbais adicionando matching-to-sample (MTS) no treino, que consistiu em um treino de emparelhamento de uma figura com a figura modelo da categoria (o experimentador mostrou a figura e o participante precisou emparelhar a figura com o modelo da categoria a qual ela pertence, ex.: mostra a figura de uma boca, e ele emparelha com o modelo de orelha para partes do corpo, ao invés de carro que é um modelo da categoria de meio de transportes), para testar o surgimento de intraverbal em duas crianças com TEA. Os estímulos consistiram de nove figuras para cada uma das quatro categorias. As categorias eram diferentes para cada uma das crianças, sendo: meio de transporte, itens de banheiro, partes do corpo e instrumentos musicais 
para um participante; e para a outra, foram móveis, meios de transporte, roupas e partes do corpo.

O objetivo dos testes de intraverbal era determinar se os participantes responderiam corretamente às questões referentes às categorias (ex.: «me fale um meio de transporte») antes e depois do treino. Cada uma das questões era apresentada três vezes, de forma randomizada (ex.: «me fale meio de transporte», «diga itens de banheiro», «fale partes do corpo» e «diga instrumentos musicais», depois «me fale instrumentos musicais», «diga meios de transporte, «me fale itens do banheiro» e «me fale partes do corpo», etc). Era solicitado que nomeassem as perguntas sem as figuras presentes, somente a partir do Sd vocal, não haviam consequências programadas para acerto e erro, os experimentadores apenas registravam e passavam para a próxima pergunta até que o sonda era encerrada.

O treino foi dividido em três partes: instrução de tato simples, instrução de categoria de tato e MTS. Na primeira, eles foram ensinados a nomear itens apresentados nas 36 figuras, em dois blocos consecutivos e de forma randomizada. Uma tentativa começava quando a figura era apresentada e se perguntava «O que é isto?». Quando uma resposta incorreta ocorria (ou nenhuma resposta), o investigador usava uma hierarquia de dicas de dois passos: ajuda intraverbal (isto é, «pas» para «pasta de dente») e uma ajuda ecoica (isto é, "pasta de dente»), se o participante não respondia a uma dica intraverbal. A tentativa então era repetida, usando um atraso de dica de $3 \mathrm{~s}$, enquanto o participante respondia corretamente na ausência da dica.

$\mathrm{Na}$ instrução de tato de categoria os participantes foram ensinados a emitir o nome correto da categoria quando mostrada cada uma das 36 figuras. A instrução começou com uma categoria. Depois do critério, a segunda categoria era adicionada e randomizada com a primeira, o mesmo era feito para as demais categorias. Durante o procedimento de MTS, eles eram ensinados a emparelhar as cartas de acordo com a categoria, sendo o estímulo modelo uma figura de uma categoria. As figuras eram randomizadas em arranjos de quatro estímulos.

Os resultados indicaram emergência e aumento de quantidade de intraverbais não treinados diretamente por meio do ensino do tato dos itens e da categorização. $\mathrm{O}$ estudo não definiu se ambas as habilidades (tato e MTS) eram necessárias para a emergência de intraverbal.

Ainda com relação aos intraverbais que emergem por meio do ensino de tato de categorias, Cihon, White, Zimmerman, Gesick, Stordahl e Eshleman (2017) aliaram Ensino Preciso (Precision Teaching) a este procedimento. Ensino Preciso é um conjunto de procedimentos sistemáticos para medir e facilitar a tomada de decisões, complementando um currículo existente e o ensino por meio de um sistema de medida responsivo e com medidas diárias, diretas e contínuas de um currículo específico (Kubina, Morrison, \& Lee, 2002). Em Ensino Preciso, a porcentagem de acertos não é a medida que garante aprendizagem de uma habilidade, mas sim a fluência (que avalia uma relação entre acurácia de respostas e tempo). A fluência comportamental pode ser acessada através das sondas dos componentes do anagrama RESA: Retention (retenção), Endurance (performance em períodos prolongados de tempo), Stability (resistência da performance diante de distratores), Application (processo em que comportamentos componentes se combinam e afetam comportamento composto). Lokke, G. E., Lokke, J. A., \& Arntzen, E. (2008).

Cihon et al. (2017) interviram com uma criança com TEA que nomeava menos de 10 figuras (correlacionadas tematicamente) em 15 s e não nomeava as categorias. Foram selecionadas quatro categorias: meios de transporte, materiais escolares, móveis e ferramentas. Os arranjos variavam de 15 a 21 imagens. Na primeira etapa, realizaram uma sonda de intraverbal. Após, era iniciado treino de fluência de tato. Para cada categoria, o pesquisador apontava e nomeava três figuras que ela tinha nomeado incorretamente na sessão anterior e pedia que ecoasse. Era colocada uma meta: "você precisa nomear 10 figuras em 15 segundos para ganhar [bolhas]!" (aumento de 1 item da meta atingida anteriormente). Quando chegava entre 50 a 100 respostas corretas em 1 minuto para uma categoria, e mantinha esse desempenho estável, eram realizadas sondas de endurance, stability e retention para a categoria. Endurance tem o objetivo de verificar se o desempenho continuará em frequência similar para períodos de tempo maiores do que aqueles que a habilidade foi praticada. Stability foi avaliada com distratores visuais e auditivos presentes 
no ambiente. Retention foi realizada um mês após ter adquirido a frequência alvo. $\mathrm{O}$ desempenho em retention, endurance e stability foi considerado fluente quando maior que 30 respostas corretas por minuto. Application foi acessado pela avaliação de intraverbal, uma vez que treinavam a habilidade componente de tato e verificavam emergência da habilidade componente de intraverbal.

Os resultados mostraram que as respostas de intraverbal de todas as categorias permaneceram perto de zero até que o critério de endurance e stability foi colocado para as respostas de tato. As provas de retenção sugerem que o repertório de tato estabelecido se manteve em níveis fluentes. Os resultados demonstram uma relação funcional entre o Treino de Fluência de Tato e o responder intraverbal, uma vez que através do treino de fluência de tato (habilidade componente) o participante teve emergência de intraverbal (habilidade composta).

O estudo de Cihon et al. (2017) apresenta algumas limitações, como colocar quantidades variadas de estímulos em cada categoria. Controlar o número de estímulos não verbais no arranjo de tato pode permitir que surjam respostas de intraverbal corretas diferentes das que foram ensinadas como tato, já que há uma quantidade limitada de itens por categoria e também há a possibilidade de terem sido ensinados os itens mais cotidianos e usuais, deixando para possível generalização apenas itens mais incomuns desconhecidos pela criança. $\mathrm{O}$ estudo conclui afirmando que os procedimentos de transferência de controle de estímulos, pelo menos para as relações de intraverbais temáticos, pode não ser necessária se as habilidades componentes (tato) forem trazidas a níveis fluentes.

Diante disso, o objetivo deste estudo é avaliar os efeitos do treino de fluência de tato na emergência de intraverbais em uma criança com TEA.

\section{Método}

\section{Participante}

Participou deste estudo um menino de 7 anos diagnosticado com TEA, com VBMAPP completo nos níveis 1,2 e 3 . Ele emitia tatos com mais de 4 palavras (artigo + sujeito + verbo + componente) e intraverbais treinados, mas não apresentava intraver- bais que não tivessem sido diretamente treinados. O critério de inclusão foi: nomear menos que 10 figuras relacionadas tematicamente em 15 segundos e não nomear itens de uma categoria quando perguntado sem as imagens dos itens. Este estudo foi aprovado pelo Comitê de Ética em Pesquisa sob o número 08088718.7.0000.5377.

\section{Local}

As sessões foram conduzidas na sala de estar da casa do participante e em uma das salas de atendimento de uma clínica de intervenção comportamental. As salas da clínica eram compostas de mesa, cadeira e itens de papelaria (canetas, lápis, papel, tesoura e cola). Quando os atendimentos foram realizados na casa, os pais da criança estavam no local, mas não entraram na sala. A pesquisadora e o participante sentaram em cadeiras colocadas na frente de uma mesa a aproximadamente $0,5 \mathrm{~m}$ de distância um do outro. A pesquisadora e outra profissional foram treinadas para a aplicação correta da intervenção. *

\section{Materiais}

Foram usadas 15 figuras coloridas (de $8,5 \mathrm{~cm}$ x 11 $\mathrm{cm})$ por categoria; a categoria de monumentos históricos contou, por exemplo, com figuras da Torre Eiffel, da Catedral de Notre Dame, do Duomo, da Igreja da Sagrada Família, do Taj Mahal, do Cristo Redentor, da Ópera de Sydney, do Museu Antigo da Alemanha, do Big Ben, da Muralha da China, da Pirâmide de Gizé, da Acrópole, do Empire State, do Museu do Lincoln e Coliseu, conforme figura 1. As imagens selecionadas foram figuras de itens que pertenciam as categorias de monumentos históricos, tipos de árvores, datas comemorativas/feriados e tipos de médicos. Foram utilizados timers para medir o tempo de sessão.

Os dados de Fluência de Tato foram computados em uma folha de registro (Apêndice 1) de até 5 tentativas em que foram registrados: as tentativas, os números de acertos por tempo (em 15s e 45 s), os números das sessões e as iniciais da pesquisadora e da terapeuta que participou da coleta de dados. As variáveis referentes à habilidade de intraverbal foram registradas em uma folha de registro (Apêndice 2) de 4 tentativas, em que foram anotados os números de acertos, as tentativas, os números das sessões e as iniciais das pesquisadoras. 


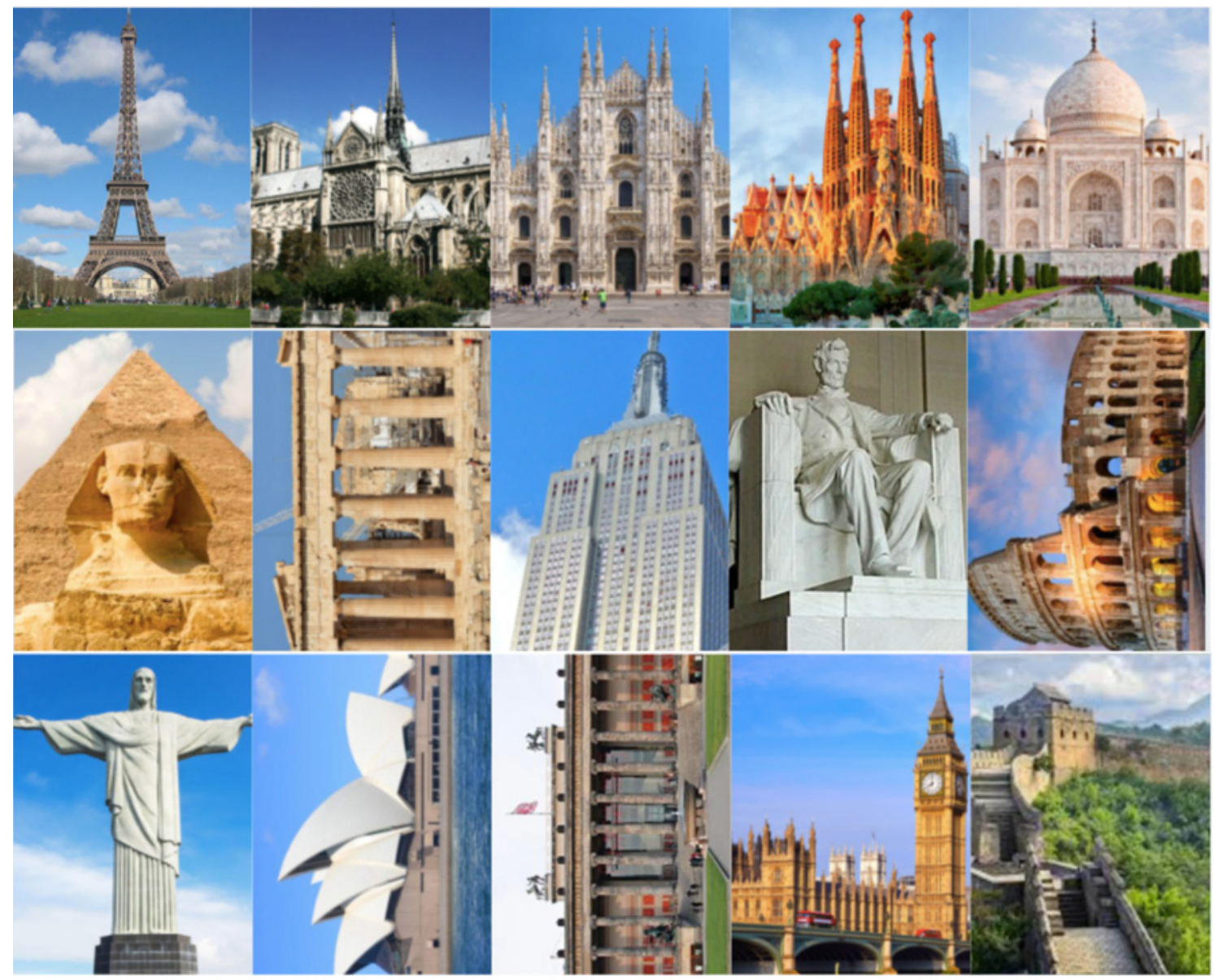

Figura 1 - Imagens da Categoria Monumentos Históricos

\section{Procedimento}

\section{Delineamento Experimental}

O delineamento realizado foi o de linha de base múltipla entre categorias temáticas. Dessa forma, somente quando uma linha de base estável era atingida para uma categoria, tinha início um treino de fluência de tato (dessa categoria). As demais permaneciam na condição de sondagem de intraverbal. Assim que outra categoria atingisse linha de base estável, o treino de tato começava e as categorias restantes eram mantidas em sondagem.

\section{Pré-teste}

As aplicadoras utilizaram as perguntas temáticas: "me fale monumentos históricos", "diga tipos de árvores", "fale tipos de médicos" e "diga datas comemorativas/feriados" e registravam as respostas para cada uma das quatro categorias.
As aplicadoras sondaram continuamente até que os dados de intraverbal estivessem estáveis em nível operante (sem tendência crescente ou decrescente) para todas as categorias às quais a resposta do participante foi a variável dependente (isto é, uma relação intraverbal). Para começar, foi especificada uma variação nos eventos antecedentes do intraverbal ("nomeie alguma [categoria], me diga alguma [categoria], me fala alguma [categoria]) e então o número de respostas corretas consecutivas (excluindo as repetidas) foram registradas. As sondas de cada categoria terminaram depois que uma resposta incorreta foi emitida ou depois de $6 \mathrm{~s}$ sem resposta. As sessões de sonda duraram menos de 5 minutos, e ocorreram a cada 3 sessões, aproximadamente. A apresentação dos intraverbais era randomizada a cada sessão (ex.:"me fale tipos de médicos/monumentos históricos/tipos de árvores/datas comemorativas") foi alternada em cada sessão sucessiva de sonda. 
Foram utilizados somente estímulos sociais, tais como: "muito bem!", “tirou nota 10!", "ótimo!” como estímulos reforçadores na condição de ensino. Para esta criança, o uso de reforçadores tangíveis não foi necessário para que ele se mantivesse respondendo, os estímulos sociais foram suficientes.

\section{Treino}

O Treino de Fluência de Tato teve início com a categoria Monumentos Históricos. As imagens eram apresentadas e seguidas pela instrução "O que é isto?". Como ele não nomeou nenhuma das cartas, o treino de tato iniciou-se com ajuda ecoica imediata. A ajuda foi sendo atrasada em 1s até que ele atingisse critério de 15 respostas corretas em uma sessão (com ou sem ajuda) ou 14 corretas (com ou sem ajuda) em 2 sessões. Posteriormente, a ajuda foi atrasada para $2 \mathrm{~s}$, até que ocorressem 15 respostas corretas independentes. Após, testou-se a quantidade de respostas de tato em 15 segundos e, a partir desta linha de base, foi estabelecido o objetivo de frequência. A cada sessão, ocorria o aumento de 1 item da meta atingida na sessão anterior. A instrução "Nomeie!" era apresentada no início das tentativas de tato para sinalizar o início da contagem de tempo (a partir da primeira resposta emitida). Caso não respondesse por 2s, era dito "Continue!". As sessões de treino duraram não mais que $10 \mathrm{mi}$ nutos, no total.

As respostas corretas e incorretas foram registradas durante $15 \mathrm{~s}$ de treino. As respostas corretas consistiram em nomear de maneira precisa (topografia correta) cada uma das figuras, (a) quando ele tivesse sido instruído para começar, (b) nomeando imediatamente a figura à direita daquela que ele tinha acabado de responder e (c) e a posição mais à esquerda da coluna logo abaixo àquela que ele tinha acabado de completar. Após completar uma fileira de 5 estímulos, recebia elogios. Elogios também eram apresentados se atingisse a meta (isto é, pelo menos uma resposta correta a mais do que na sessão anterior). Se não atingisse a meta, eram realizadas até mais 4 tentativas. Se não atingisse ainda assim, voltava a fazer a atividade que ocorria antes da sessão (desenho livre).
As sessões de treino sempre duraram 15s, e o número de respostas corretas e incorretas foi convertido em frequência (isto é, 10 respostas corretas em 15s). O treino de tato ocorria para a categoria seguinte da mesma maneira. Os arranjos dos estímulos em fileiras variavam quanto à ordem para diminuir a probabilidade de memorização de sequência de respostas.

\section{Pós-Teste}

Para determinar se a fluência tinha sido atingida, os componentes de manutenção (retention), persistência (endurance) e estabilidade (stability) do RESAA [Kubina et al. (2002)] foram avaliados. Uma vez atingido o alvo de frequência (10 respostas corretas em $15 \mathrm{~s}$, sem erros) para uma categoria, foram testadas a persistência e estabilidade, respectivamente. Um mês após ter atingido a frequência alvo, foi testada a manutenção (retention). A sonda de persistência (endurance) foi feita em com um tempo três vezes mais longo do que a duração de treino (45s), e avaliou se o desempenho continuou em frequências similares para períodos maiores de tempo do que aquele de treino (10 em 15s). A estabilidade (stability) foi avaliada no tempo de sessão (10 em 15s) enquanto distratores visuais e auditivos estavam presentes no ambiente (vídeos de carros em um celular em frente ao participante). Os desempenhos em manutenção, persistência e estabilidade deveriam atingir os critérios de fluência. A aplicação (application) foi avaliada ao longo das provas de intraverbal. Para cada categoria, o mesmo pós-teste era ser realizado.

\section{Resultados}

\section{Pré-teste e Treino}

O primeiro pré-teste realizado foi o de Tato para a categoria de Monumentos Históricos e o participante não soube nomear nenhuma das 15 figuras. Teve início, então, o treino de tato. Ao todo, foram 6 sessões para emissão de 15 respostas corretas independentes para esta categoria, conforme Figura 2. 

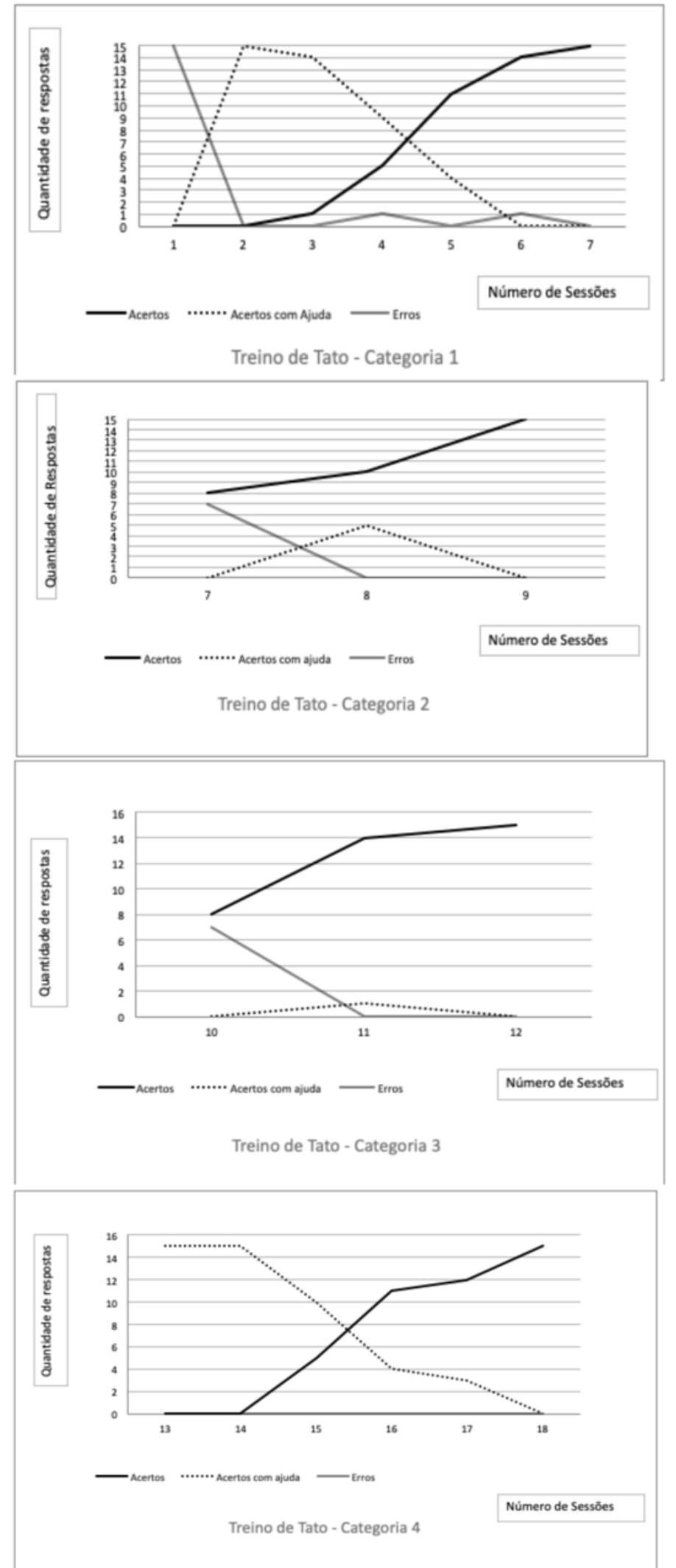

Figura 2 - Número de acertos, acertos com ajuda e erros, por sessão, durante treino de tato das Categorias 1, 2, 3 e 4.
Após, iniciou-se o Treino de Fluência de Tato para a Categoria 1. Na primeira sessão emitiu 11 respostas em 15s, conforme figura 3.

\section{Pós-Teste}

A sonda de persistência foi realizada em 45 segundos. Na primeira sessão, ocorreram 28 respostas corretas sem erros; na segunda, foram 26; na terceira, 27, e, na quarta, atingiu o alvo de 30 respostas corretas em 45 segundos. Para a sonda de estabilidade, na primeira sessão, atingiu o alvo de 10 respostas corretas em 15 segundos com distratores presentes.

$\mathrm{Na}$ sessão 7, iniciou-se também o treino de tato para a categoria 2: tipos de árvores. Foram necessárias mais duas sessões de treino de tato para que ele atingisse o critério (sessão 9 - 15 respostas independentes). A frequência alvo foi atingida já na primeira sessão de treino de fluência de tato $(10 \mathrm{em}$ 15s). Na sessão de sonda de persistência, obteve critério na primeira tentativa, e o mesmo ocorreu na primeira sonda de estabilidade.

Para a categoria 3 (feriados ou datas comemorativas), precisou de 2 sessões de treino de tato até independência. No treino de fluência de tato, atingiu o critério na primeira sessão, assim como em persistência e estabilidade.

Posteriormente, teve início a categoria 4 (tipos de médicos). Foram necessárias cinco sessões de treino de tato para que atingisse critério de 15 respostas independentes. Posteriormente, realizou-se o treino de fluência de tato em 15s, no qual ele emitiu 10 respostas. Na sonda de persistência, em 45 segundos foram emitidas 30 respostas corretas. $\mathrm{Na}$ estabilidade, ocorreram 40 respostas por minuto.

A Figura 3 mostra os resultados das sondas em todas as categorias, com número de respostas intraverbais corretas (linha tracejada), por sessão, assim como o número de respostas de tato por minuto (linha contínua). 


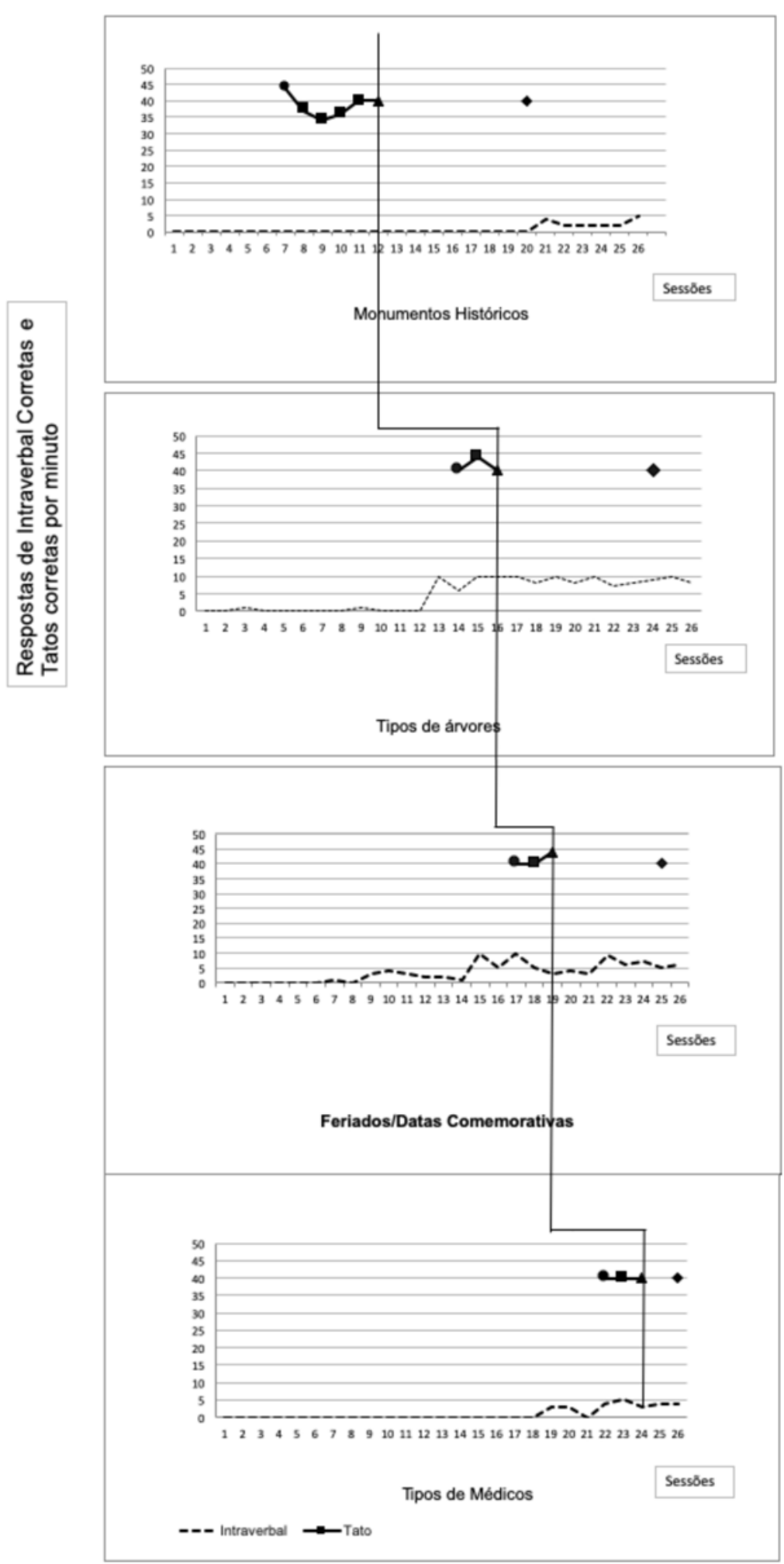

- Treino de Fluência

- Persistência

Estabilidade

- Retençắo

Figura 3 - Número de respostas corretas de intraverbal e de tato, nas sondas, por categoria, durante as sessões. 
Observa-se que, para a categoria 1, o critério de fluência foi adquirido já na primeira sessão. $\mathrm{O}$ participante atingiu persistência após três sessões e estabilidade em uma sessão. Contudo, a emergência de intraverbal só ocorreu após a sonda de retenção, tendo apresentado, pelo menos, uma resposta intraverbal para a categoria a partir de então.

$\mathrm{Na}$ segunda categoria, observa-se emergência de intraverbal a partir do treino de tato, sessão 13, em quantidade superior à linha de base. Fluência, persistência e estabilidade no treino de fluência de tato ocorreram na sessão 14,15 e 16 respectivamente. Como os intraverbais foram avaliados no início da sessão, o impacto do critério pode ser visto a partir da sessão 15, na qual apresentou 10 (dos 15 possíveis) intraverbais e variou a quantidade de intraverbais emitidos, até retenção.

$\mathrm{Na}$ terceira categoria, também houve emergência de intraverbal a partir do treino de tato, antes do treino de fluência. Atingiu fluência na sessão 16, persistência na sessão 17 e estabilidade na sessão 18 e o número de intraverbais se manteve constante até o final da sonda de estabilidade, com variação nas sessões posteriores.

$\mathrm{Na}$ quarta categoria, ocorreu emergência de intraverbal no treino de tato na sessão 19 , aumento na quantidade de intraverbais após persistência, tendo uma queda pequena em estabilidade. A fluência ocorreu na sessão 22, seguida de persistência e estabilidade (sessões 23 e 24).

O treino de fluência da categoria 1 , provocou aumento de respostas intraverbais na categoria 3 , o que pode indicar que o ensino de tato de uma categoria pode ter interferido em outras categorias também. A partir da sonda de persistência da categoria 1, ocorreu aumento para 4 respostas intraverbais da categoria 3 .

A emergência de intraverbal ocorreu na segunda sessão de tato para todas as categorias, exceto monumentos históricos (ocorreu somente após retenção). Além disso, o participante apresentou respostas intraverbais cujos tatos não foram treinados: para monumentos históricos, "estátua do ibirapuera"; para tipos de árvores, "tomateiro" e "pessegueiro"; para feriados/datas comemorativas, "aniversários de pessoas".

\section{Discussão}

Os resultados indicam que o ensino de tatos tematicamente relacionados com uso de Ensino Preciso resultou em emergência de intraverbais. Como pode-se constatar, houve a emergência de, pelo menos, cinco respostas em todos os intraverbais. Além disto, tanto o tato quanto o intraverbal se mantiveram no repertório da criança, mesmo após encerrado o treino (na retenção).

Assim como em Cihon et al. (2017), os intraverbais de todas as categorias temáticas começaram a ter emergência após inserção do treino de fluência e das sondas de Ensino Preciso (principalmente para as categorias 1 e 2). Na pesquisa de Cihon et al. (2017), os critérios mais críticos foram de persistência e estabilidade.

Conforme a literatura acima destacada, os resultados nas provas de retenção também sugerem que o repertório de tato estabelecido se manteve fluente após encerrado o treino de fluência. Os resultados demonstram uma possível relação funcional entre o Treino de Fluência de Tato e o responder intraverbal, uma vez que somente o treino de fluência de habilidades componentes (tato) produziu emergência de intraverbais (habilidades compostas), sem necessidade de treino direto. O presente estudo manteve a quantidade de estímulos fixa (15) a fim de possibilitar a ocorrência de intraverbais e também utilizou as figuras sem instruções durante o treino de tato e fluência (sem o uso de "me fale __," por exemplo), exceto no início para sinalizar o começo da contagem do tempo. Estudos posteriores poderiam verificar emergência de categorizações para crianças que ainda não emitem intraverbais de categorias (ex.: "fale __, para crianças que ainda não respondem à nenhuma categoria). Também seria possível avaliar se o treino direto de intraverbal para determinadas categorias e o uso de Ensino Preciso com treino de fluência de tato para outras categorias poderiam mostram diferenças no tempo de treino necessário para aquisição e na generalidade.

O participante do presente estudo já realizava intraverbais para outras categorias, o que possivelmente favoreceu na velocidade para alcance dos resultados finais. Além disso, a criança estava em intervenção terapêutica com as aplicadoras antes do estudo, e já tinha uma história de reforçamento com 
seguimento de instruções e possibilidade de uso de somente estímulos sociais como reforçadores, e de forma intermitente. Manter outros indivíduos, que não tenham história semelhante, em condições de testes que exigem diversas respostas consecutivas, pode ser um desafio para outros estudos.

Para a ocorrência de intraverbais do tipo que foi requerido, é necessário repertório de nomeações (vocabulário). Aprender a seguir instruções verbais com respostas verbais, possivelmente facilita a aquisição de categorizações desse tipo após treino de nomeações de itens dessas categorias, já que ambos os repertórios verbais investigados aqui, definidos como tatos e intraverbais, foram solicitados à criança em condição artificial (não natural), por meio de instruções. Esse é um limite do presente estudo, que não investigou se o treino de tato (nomeações de figuras após instrução) possibilitaria a emergência de intraverbais do tipo investigado em condições naturais nas quais esse repertório fosse requerido sem instrução verbal. Além disso, as sondas de Ensino Preciso também foram realizada em condições similares às sessões terapêuticas do participante, nas quais o seguimento de instrução já tem uma história de reforçamento. Assim, os resultados não permitem afirmar que o desempenho da criança em condições nas quais esse repertório pudesse ser utilizado fora do ambiente de pesquisa e terapêutico, sem instrução, ocorreria.

Ainda, os intraverbais não surgiriam sem que o participante fosse capaz de nomear itens das categorias treinadas, e o treino de tato permitiu a formação de classes de estímulos que foram solicitadas posteriormente na forma de intraverbais. Não é possível afirmar que os intraverbais emergeriam se o treino de tato envolvesse as figuras das categorias misturadas umas às outras, sem que a propriedade comum à classe de estímulos fosse destacada/sinalizada de alguma maneira (neste estudo, temporalmente - uma de cada vez, e também visualmente - figuras da mesma classe apresentadas sempre juntas).

\section{Referências Bibliográficas}

American Psychiatric Association. (2013). Diagnostic and statistical manual of mental disorders $\left(D S M-5^{\oplus}\right)$. American Psychiatric Pub.
Cihon, T. M., White, R., Zimmerman, V. L., Gesick, J., Stordahl, S., \& Eshleman, J. (2017). The effects of precision teaching with textual or tact relations on intraverbal relations. Behavioral Development Bulletin, 22(1), 129.

Grannan, L., \& Rehfeldt, R. A. (2012). Emergent intraverbal responses via tact and match-to-sample instruction. Journal of Applied Behavior Analysis, 45(3), 601-605. doi: 10.1901/ jaba.2012.45-601

Lokke, G. E., Lokke, J. A., \& Arntzen, E. (2008). Precision Teaching, Frequency-Building, and Ballet Dancing. Journal of Precision Teaching and Celeration, 24, 21-27.

Kodak, T., Fuchtman, R., \& Paden, A. (2012). A comparison of intraverbal training procedures for children with autism. Journal of Applied Behavior Analysis, 45(1), 155-160.

Kubina Jr, R. M., Morrison, R., \& Lee, D. L. (2002). Benefits of adding precision teaching to behavioral interventions for students with autism. Behavioral Interventions: Theory \& Practice in Residential \& Community-Based Clinical Programs, 17(4), 233-246.

Matos, M. A. D. (1991). As categorias formais de comportamento verbal em Skinner. Anais da XXI Reunião Anual da Sociedade de Psicologia de Ribeirão Preto, 1991, 333-341.

McMorrow, M. J., Foxx, R. M., Faw, G. D., \& Bittle, R. G. (1987). Cues-pause-point language training: Teaching echolalics functional use of their verbal labeling repertoires. Journal of Applied Behavior Analysis, 20(1), 11-22.

Skinner, B. F. (1957). Verbal behavior. New York: Appleton-Century-Crofts.

\section{Informações do Artigo}

\section{Histórico do artigo:}

Submetido em:19 de novembro de 2019

Primeira decisão editorial: 28 de Julho de 2020

Aceite final: 5 de Novembro de 2020

Editor Associado: Adriano Alves Barboza 